\title{
Multi-Objective Optimal Charging Method for Lithium-Ion Batteries
}

\author{
Xiaogang $\mathrm{Wu}^{1,2, *}$, Wenwen Shi ${ }^{1,3}$ (i) and Jiuyu $\mathrm{Du}^{3}$ \\ 1 College of Electrical and Electronics Engineering, Harbin University of Science and Technology, \\ Harbin 150080, China; sww4536@163.com \\ 2 State Key Laboratory of Power Transmission Equipment \& System Security and New Technology, \\ Chongqing University, Chongqing 400044, China \\ 3 State Key Laboratory of Automotive Safety and Energy, Tsinghua University, Beijing 100084, China; \\ dujiuyu@tsinghua.edu.cn \\ * Correspondence: xgwu@hrbust.edu.cn; Tel.: +86-451-8639-1699
}

Academic Editor: Izumi Taniguchi

Received: 1 August 2017; Accepted: 23 August 2017; Published: 26 August 2017

\begin{abstract}
In order to optimize the charging of lithium-ion batteries, a multi-stage charging method that considers the charging time and energy loss as optimization targets has been proposed in this paper. First, a dynamic model based on a first-order circuit has been established, and the model parameters have been identified. Second, on the basis of the established model, we treat the objective function of the optimization problem as a weighted sum of charging time and energy loss. Finally, a dynamic programming algorithm (DP) has been used to calculate the charging current of the objective function. Simulation and experimental results show that the proposed charging method could effectively reduce the charging time and decrease the energy loss, compared with the constant-current constant-voltage charging method, under the premise of exerting little influence on the attenuation of battery capacity.
\end{abstract}

Keywords: lithium-ion battery; equivalent circuit model; charging optimization; dynamic programming (DP); capacity attenuation

\section{Introduction}

As the key technology of battery management systems, the charging strategy influences the battery life and safe operation [1-3]. Their long charging time is one of the main obstacles for the popularization of lithium batteries $[4,5]$. Moreover, the battery loses energy in the form of heat dissipation during the charging process, and the literature [6] indicates that within a certain temperature range, the higher the battery temperature, the more serious the battery life decay. Therefore, effective reduction of the charging time and battery energy losses during the charging period has become one of the important directions for the research on lithium-ion battery charging strategies [7-9].

The constant-current constant-voltage (CCCV) charging method is one of the most widely used charging methods; further, it is simple and easy to control. However, different charging rates and cut-off voltages result in battery aging [10]. Accordingly, a multi-stage constant current charging method for multi-objective optimization has been studied [11,12]. The target optimization mainly aims to reduce the charging time, improve the charging efficiency, and prolong the battery life; however, it is necessary to calibrate numerous experimental data and therefore, such a method is difficult to use. Reference [13] proposed a fast charging method for a lithium battery close to complete discharge. However, such a method can result in an overheated battery at the expense of battery life and requires a better solid electrolyte interface or unique electrode structures to mitigate any potential lithium plating [14-16]. References [17-20] involved the study of a pulse charging method, wherein the 
battery was stationary or discharged for a short period of time in order to slow down the polarization phenomenon during the charging process. However, the proposed method has higher requirements for the design of the charging power supply.

In order to improve the charging efficiency and prolong the battery life, a general charging voltage protocol based on battery state-of-health was proposed in [21], which aims to study the optimization of charging current. Moreover, the battery charging method has also been studied in optimization problems related to charging time, battery energy loss, and temperature rise in some studies. The effect of cut-off voltage, ambient temperature, and battery aging on the charging optimization results was also discussed in [22], whereas the influence of charge current on the Ohmic resistance, polarization resistor, and polarization capacitance of the battery has not been fully considered yet. Although battery charging current has been optimized from the perspective of charging time and battery energy losses in $[23,24]$, the battery model that has been adopted is the voltage-resistor model, which ignores the influence of polarization phenomena on charging.

In summary, previous battery charge management studies mainly concentrated on the optimization of the charging current. In spite of the fact that some of them considered charging time and energy loss as characteristics of the charging method, the effect of the change of battery model parameters on the optimization of charging current was not considered during the optimization process. Based on the dynamic model of the equivalent circuit, a lithium cobalt-acid battery has been considered as the research objective in this study. Moreover, considering the influence of the model parameters on the state of charge (SOC) and charging current and considering the charging time and battery energy loss as the optimal targets, over-voltage is employed as a state variable, and a dynamic programming algorithm is also adopted to obtain the optimized charging current. Further, the influence of variable weighting factors on the optimization result is also discussed in this paper.

\section{Lithium-Ion Battery Testing and Modeling}

\subsection{Charging Principle and Model Selection}

In this study, a lithium cobalt acid battery is selected as the research object. Its details are listed in Table 1.

Table 1. Nominal specifications of the battery.

\begin{tabular}{cc}
\hline Item & Specification \\
\hline Cathode material & $\mathrm{LiCoO}_{2}$ \\
Anode material & $\mathrm{Graphite}$ \\
Rated capacity & $2.6 \mathrm{Ah}$ \\
Maximum charging current & $1 \mathrm{C}$ \\
Maximum discharging current & $2 \mathrm{C}$ \\
Charging cut-off voltage & $4.2 \mathrm{~V}$ \\
Discharging cut-off voltage & $3.75 \mathrm{~V}$ \\
\hline
\end{tabular}

A lithium-ion battery consists of three parts: the anode lithium compound, its intermediate electrolyte membrane, and cathode carbon. When it is charged, lithium ions are generated at the anode and embedded through the electrolyte membrane into the cathode material. As more lithium ions are embedded into the cathode material, the SOC level of the battery becomes higher. The chemical reaction during the lithium-ion battery charging process is given as follows:

$$
3 \mathrm{C}+\mathrm{LiCoO}_{2} \leftrightarrow 0.5 \mathrm{LiC}_{6}+\mathrm{Li}_{0.5} \mathrm{CoO}_{2}
$$

Moreover, during the battery charging process, since the lithium ion concentration fails to reach a balance within a short period of time, a voltage difference, i.e., the over-voltage, arises. In order to describe the charging process accurately, many battery models have been established in previous studies in order to reflect the mechanism changes in the charging process. Common lithium battery 
models include an equivalent circuit model and an electrochemical model; further, the equivalent circuit model is simple and can accurately reflect the running state of the battery $[25,26]$. Therefore, this study refers to literature $[27,28]$, and the first-order equivalent circuit model has been chosen as the research object, as shown in Figure 1.

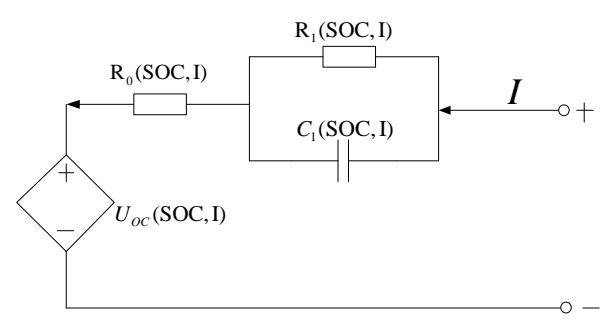

Figure 1. First-order circuit model of battery.

As shown in Figure 1, the equivalent circuit model of the battery consists of the following parts: open-circuit voltage which is a controlled voltage source $U_{O C}$, Ohmic resistance $R_{0}$, polarization resistance $R_{1}$, and polarization capacitance $C_{1}$. According to [29], all the parameters in the model are related to the SOC and charge-discharge ratio of the battery under the condition of fixed ambient temperature.

\subsection{Parameter Identification and Verification of Battery Model}

In order to identify the parameters of the model for different SOC and charging ratios, the battery have been tested with several sets of specific charging ratios by adopting the flowchart shown in Figure 2.

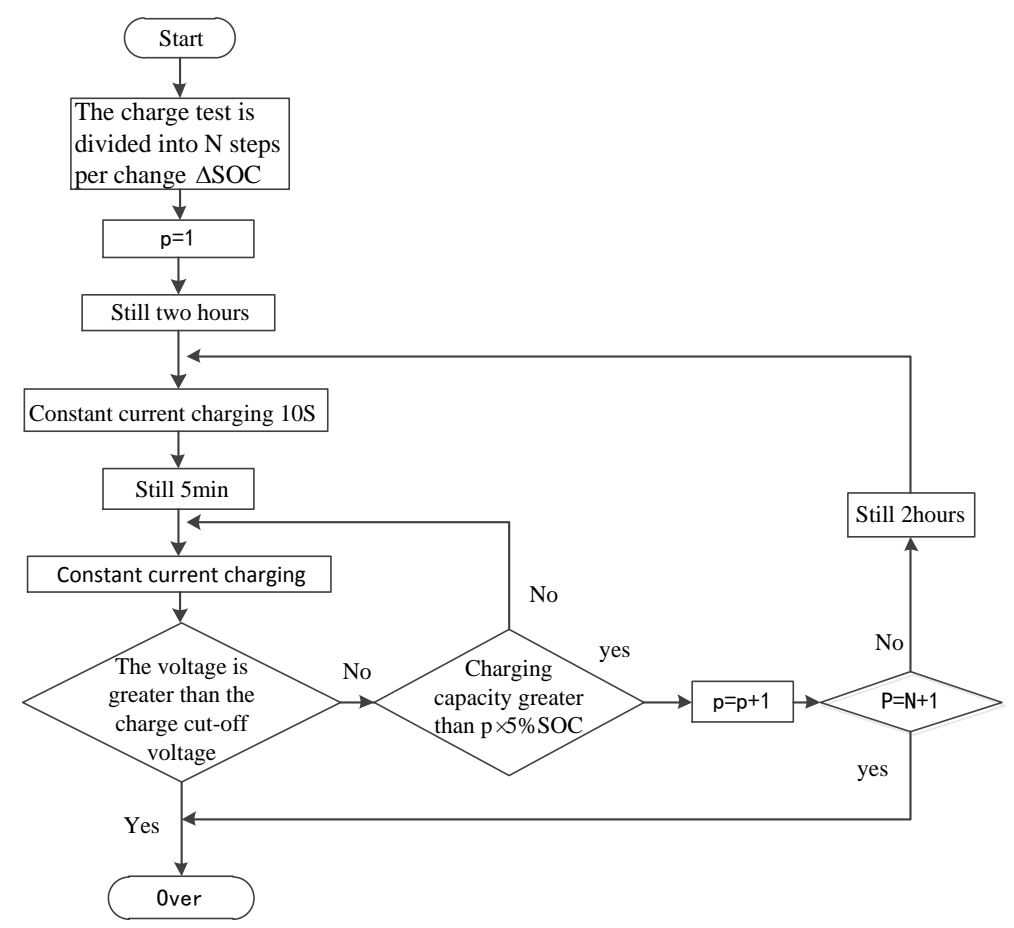

Figure 2. Test flow of battery model parameters.

As evident from the test flow in Figure 2, in each test, the battery has been subjected to a charge process with a pulse of $10 \mathrm{~s}$ for every SOC of $5 \%$. After the charging test is completed, the relationship between the battery terminal voltage and charging current corresponding to each pulse charging 
stage is fitted by using the least squares method mentioned in [30]. The corresponding parameter identification results of the battery model are shown in Figure 3.

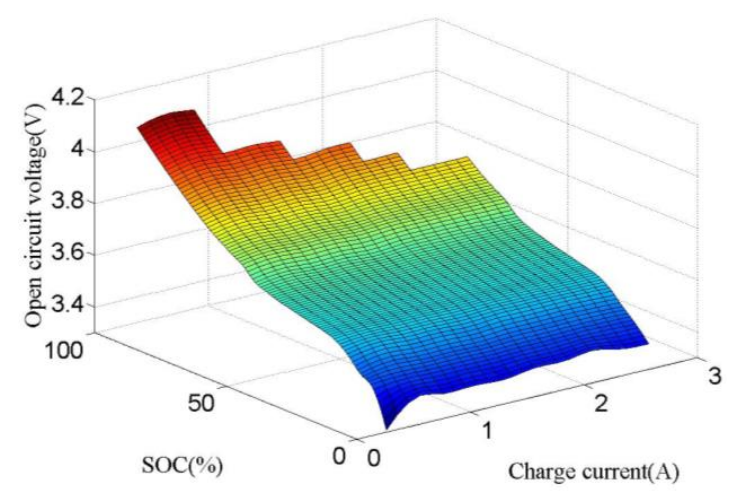

(a)

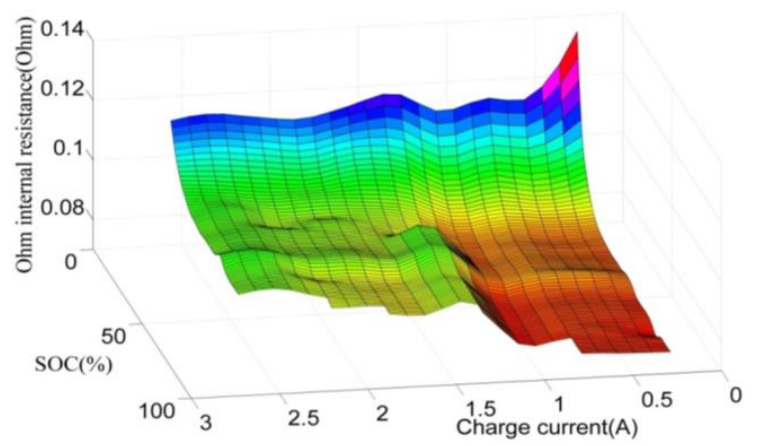

(b)

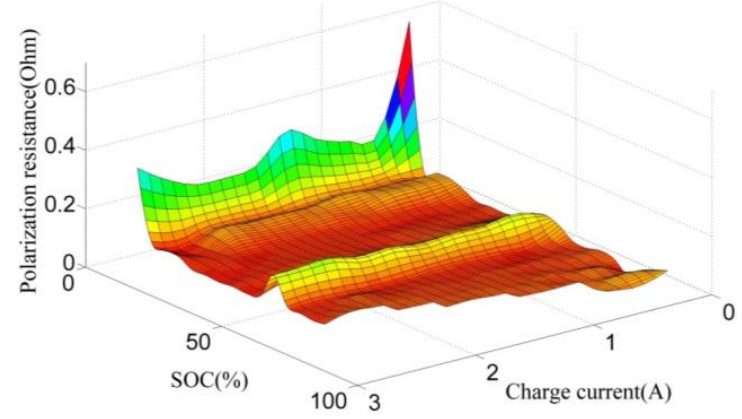

(c)

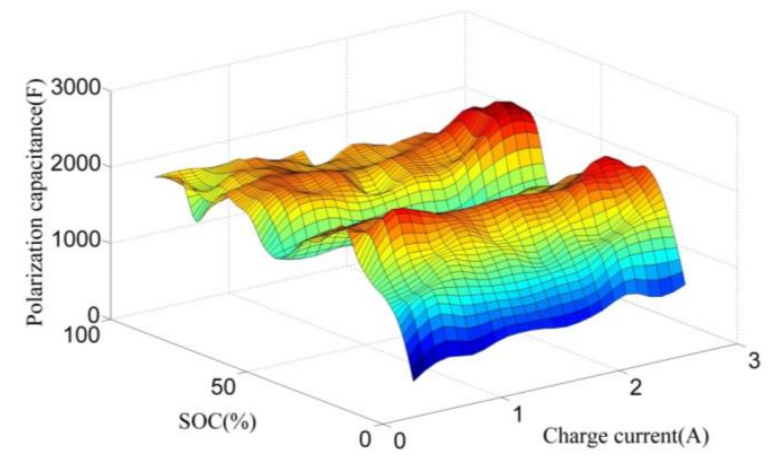

(d)

Figure 3. Identification results of battery model parameters. (a) Open circuit voltage identification results; (b) Ohmic resistance identification results; (c) Polarization resistance identification results; (d) Polarization capacitance identification results. 
In order to verify the accuracy of the model parameters, this study selects charging current with different specific ratios to simulate the intermittent charging of the battery based on the targeted dynamic model. Firstly, the equivalent circuit model of a battery was established under Matlab/Simulink, and the charging simulation was carried out by using some specific current. Secondly the battery is tested with the same current as the simulation. Finally we compare the battery terminal voltage between simulation and test. Considering the simulation and actual test with charging ratio of $0.4 \mathrm{C}$ as an example, the current and voltage curves are shown in Figure 4 . Figure 5 illustrates a comparison between the errors of the calculated model value and the actual test battery result with various charging ratios. The error is calculated as:

$$
\tau_{\mathrm{t}}=\frac{\left|\mathrm{U}_{\mathrm{t}, \mathrm{r}}-\mathrm{U}_{\mathrm{t}, \mathrm{s}}\right|}{\mathrm{U}_{\mathrm{t}, \mathrm{r}}} \times 100 \%
$$

where $U_{t, r}$ is the actual value of the battery terminal voltage at time $t$ and $U_{t, s}$ is the simulation value.

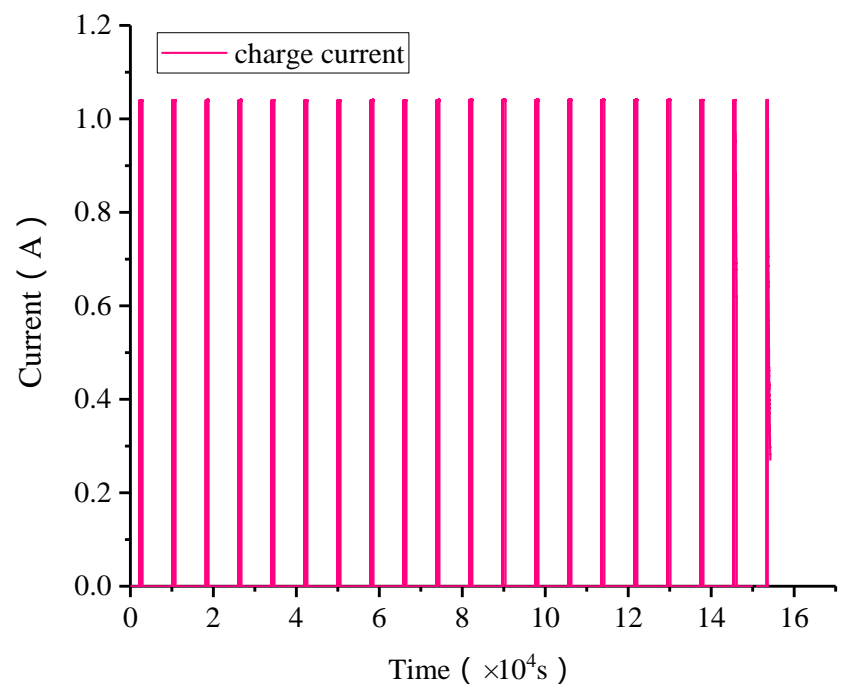

(a)

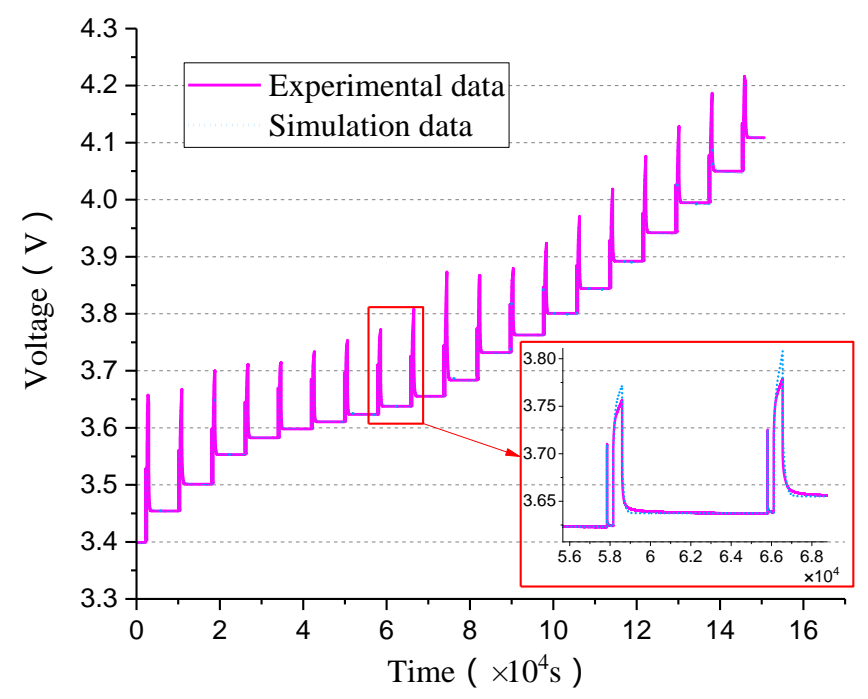

(b)

Figure 4. Simulation and test results with charging ratio of 0. 4C. (a) Charging current curve; (b) Voltage curves for simulation and testing. 


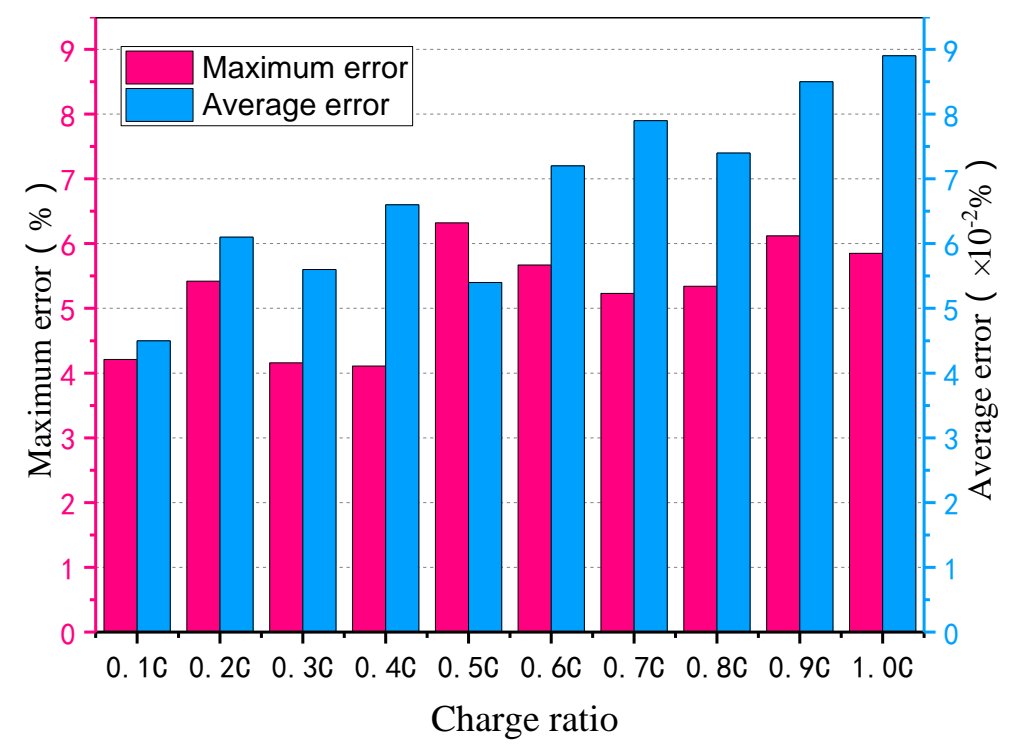

Figure 5. Comparison between the errors of the calculated value and the test result of the equivalent circuit model.

It is evident from Figure 4 that the battery terminal voltage of the targeted model is quite close to the actual battery test results when the charging ratio is $0.4 \mathrm{C}$. It can be observed from Figure 5 that the average error of the battery terminal voltage calculated using the targeted model relative to the actual voltage is less than $0.1 \%$, and the maximum error is less than or equal to $6.12 \%$ with different charging ratios. Therefore, it can be demonstrated that the targeted battery dynamic model can accurately represent the parameter change of the battery charging process.

\section{Multi-Objective Optimal Charging Method}

During the battery charging, the charging time and battery energy loss are important indexes to evaluate the charging method. When analyzing the charging process using the first-order equivalent circuit battery model, the battery's energy loss originates from the Ohmic resistance and polarized internal resistance. However, the charging time is usually inversely proportional to the charging ratio [31]. The key problem of the charging method is to balance the charging time and battery energy loss.

\subsection{Determination of the Boundary Condition of Charging Current}

Zhang et al. [32] observed that the maximum charge current of a lithium-ion battery is usually related to the current SOC. Accordingly, this study performs many charging tests, and subsequently, the test results are fitted; finally, the maximum charge current corresponding to the SOC is obtained. By using the test flow shown in Figure 6, the maximum charge capacity corresponding to the charge current ratio in the range of $0.1 \mathrm{C}-1 \mathrm{C}$ can be obtained. The ratio of maximum charge capacity to the rated capacity, i.e., $\xi$, or in other words, the percentage of maximum charge capacity, serves as an independent variable, and the charging current acts as a dependent variable to obtain a fitting. Thus, the fitted curve shown in Figure 7 is obtained, and the results are given as follows:

$$
\mathrm{I}_{\max }(\xi)= \begin{cases}1 & \xi \leq 74.65 \% \\ -0.093 \xi+9.5 & \xi>74.65 \%\end{cases}
$$

According to [33,34], when the charging current is greater than the security threshold corresponding to the current SOC, the battery aging accelerates or heat might arise out of the 
control. In order to avoid damage to the battery, the maximum charge current corresponding to the aforementioned charge capacity $\xi$ is considered as the boundary condition of the charging current selection for different $\mathrm{SOC}$, i.e.,

$$
\mathrm{I}_{\max }(\mathrm{SOC})= \begin{cases}1 & \mathrm{SOC} \leq 74.65 \% \\ -0.093 \times \mathrm{SOC}+9.5 & \mathrm{SOC}>74.65 \%\end{cases}
$$

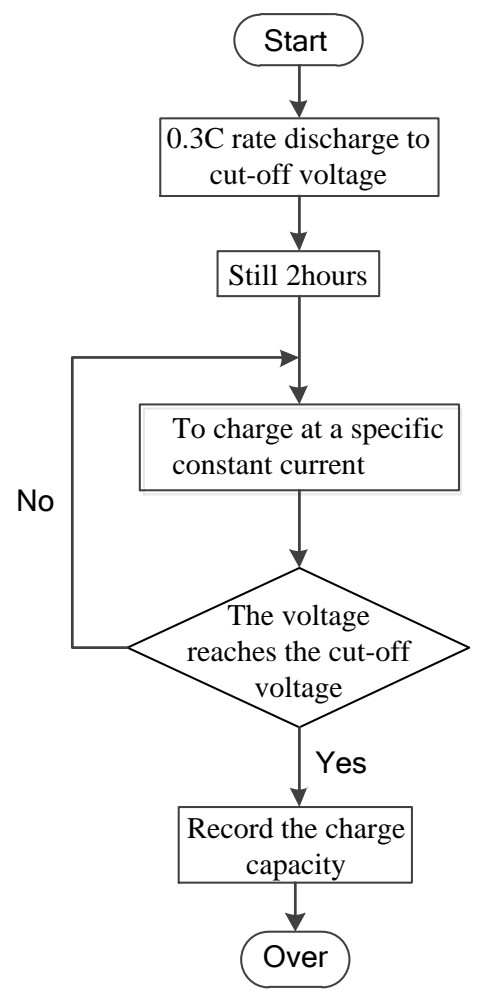

Figure 6. Test flow for the maximum charge capacity with different charging currents.

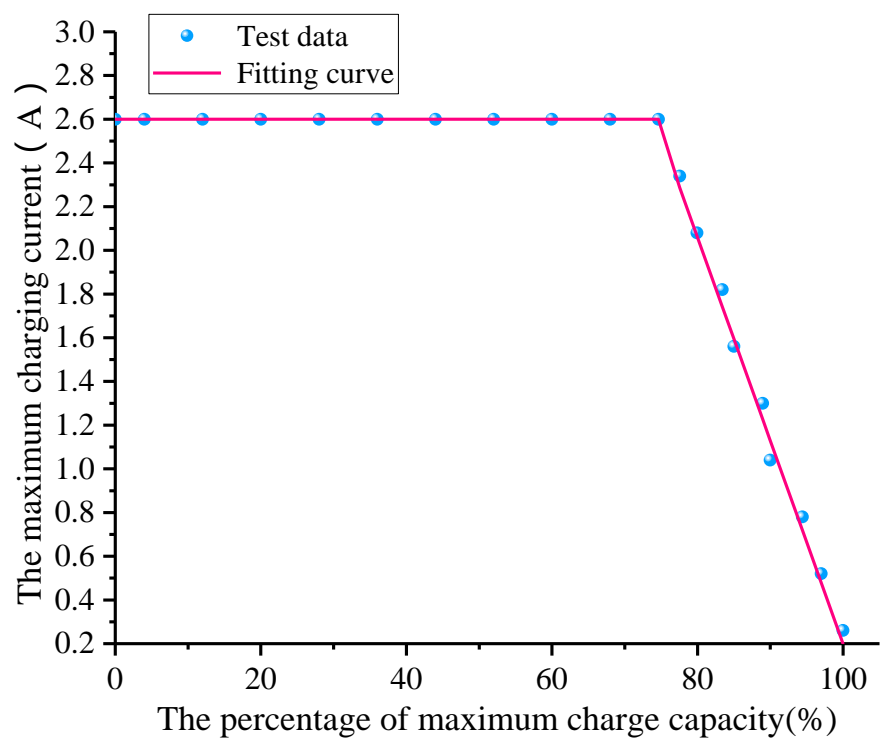

Figure 7. Relationship between the maximum charge capacity and its corresponding maximum charge current. 


\subsection{Establishment of Optimization Objective Function}

This study considers the battery energy loss and charging time as the optimization objective function. During the process of formulating this function, the charging process is first divided into $\mathrm{N}$ constant current charging stages, and the parameters of the model are constant in each charging stage. During the entire charging process, the battery's energy loss can be expressed as:

$$
\mathrm{W}=\sum_{\mathrm{j}=1}^{\mathrm{N}}\left[\mathrm{I}_{\mathrm{j}}^{2} \mathrm{R}_{0, \mathrm{j}}\left(\mathrm{I}_{\mathrm{j}}\right) \Delta_{\mathrm{j}}+\mathrm{W}_{1, \mathrm{j}}\right]
$$

where $I_{j}$ represents the charge current in the jth charging phase, and $R_{0, j}\left(I_{j}\right)$ represents the corresponding Ohmic resistance of the jth phase, which is affected by the current SOC and charging current. Furthermore, $W_{1, j}$ is the energy loss of the polarization resistance in the jth phase, which is related to the charging current $I_{j}$, polarization capacitance $C_{1, j}\left(I_{j}\right)$, and polarization resistance $R_{1, j}\left(I_{j}\right)$ of the current stage; further, $\Delta_{\mathrm{j}}$ indicates the time duration of the jth charging phase.

The SOC changes in each charging phase are expressed as follows:

$$
\Delta \mathrm{SOC}=\frac{\int_{0}^{\Delta_{j}} \eta \mathrm{I}_{\mathrm{j}}(\mathrm{t}) \mathrm{dt}}{3600 \mathrm{Cap}}
$$

where Cap represents the battery rated capacity with the unit of ampere hour and $\eta$ is the Coulomb efficiency. In this paper, 1 has been taken [30], and when the charging process is divided by $1 \%$ of $\triangle \mathrm{SOC}$, the charging time of each charging phase is:

$$
\Delta_{\mathrm{j}}=\frac{36 \mathrm{Cap}}{\mathrm{I}_{\mathrm{j}}}
$$

When the sampling time of the charging system is $\Delta t$, the number of samples in each charging phase is:

$$
\mathrm{M}_{\mathrm{j}}=\frac{\Delta_{\mathrm{j}}}{\Delta \mathrm{t}}=\frac{36 \mathrm{Cap}}{\mathrm{I}_{\mathrm{j}} \Delta \mathrm{t}}
$$

The energy loss of the polarization resistance at each charging stage separated by the sampling time $\Delta \mathrm{t}$ is given as:

$$
\mathrm{W}_{1 \mathrm{j}}=\sum_{\mathrm{k}=1}^{\mathrm{M}_{\mathrm{j}}} \mathrm{I}_{1, \mathrm{j}, \mathrm{k}}^{2} \mathrm{R}_{1, \mathrm{j}}\left(\mathrm{I}_{\mathrm{j}}\right) \Delta \mathrm{t}
$$

where $I_{1, j, k}$ is the current of the polarization resistance $R_{1, j}\left(I_{j}\right)$ at the K-sampling moment in the jth charging phase. According to the full response equation of the first-order circuit, the following can be obtained:

$$
I_{1, j, k}=I_{j}\left(1-e^{-\frac{k \Delta t}{R_{1, j}\left(I_{j}\right) C_{1, j}\left(I_{j}\right)}}\right)+\frac{U_{1, j}}{R_{1, j}\left(I_{j}\right)} e^{-\frac{k \Delta t}{R_{1, j}\left(I_{j}\right) C_{1, j}^{\left(I_{j}\right)}}}
$$

where $U_{1, j}$ represents the polarization voltage at the starting point of the jth charging phase. By substituting (10) into (9), the following can be obtained:

$$
W_{1, j}=\sum_{k=1}^{M_{j}}\left(I_{j}\left(1-e^{-\frac{k \Delta t}{R_{1, j}\left(I_{j}\right) C_{1, j}\left(I_{j}\right)}}\right)+\frac{U_{1, j}}{R_{1, j}\left(I_{j}\right)} e^{-\frac{k \Delta t}{R_{1, j}\left(I_{j}\right) C_{1, j}\left(I_{j}\right)}}\right)^{2} R_{1, j}\left(I_{j}\right) \Delta t
$$


Substituting (11) into (5), the total energy consumption of the battery during multi-stage constant current charging can be obtained as:

$$
\begin{aligned}
W= & \sum_{j=1}^{N}\left[\sum_{k=1}^{M_{j}}\left(I_{j}\left(1-e^{-\frac{k \Delta t}{R_{1, j}\left(I_{j}\right) C_{1, j}\left(I_{j}\right)}}\right)+\frac{U_{1, j}}{R_{1, j}\left(I_{j}\right)} e^{-\frac{k \Delta t}{R_{1, j}\left(I_{j}\right) C_{1, j}\left(I_{j}\right)}}\right)^{2} R_{1, j}\left(I_{j}\right) \Delta t\right. \\
& \left.+I_{j}{ }^{2} R_{j}\left(I_{j}\right) \Delta \Delta_{j}\right]
\end{aligned}
$$

During the entire charging process, the charging time of the battery is:

$$
\mathrm{T}=\sum_{\mathrm{j}=1}^{\mathrm{N}} \frac{36 \text { Cap }}{\mathrm{I}_{\mathrm{j}}}
$$

By setting the sampling time of the system as $\Delta t=1 \mathrm{~s}$, the objective function of the optimized charging method presented in this paper can be expressed as:

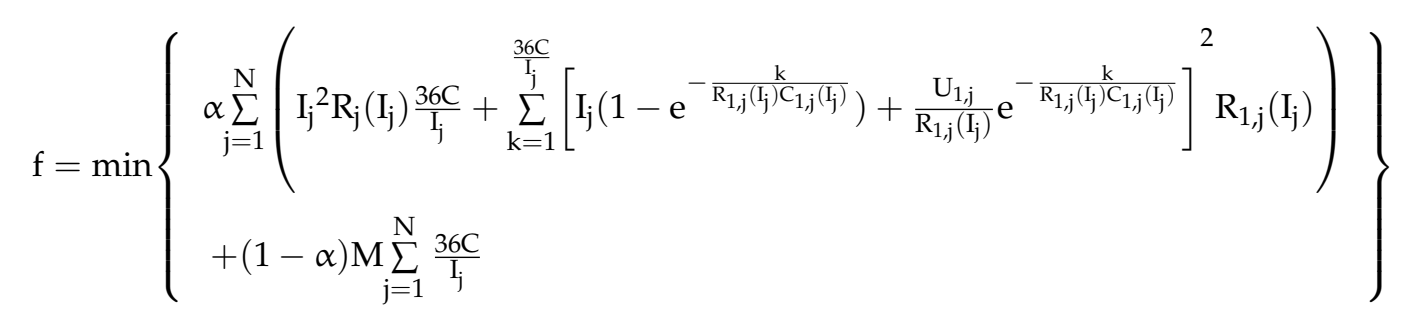

The following can be obtained after further simplification:

$$
f=\min \left\{\begin{array}{l}
\sum_{j=1}^{N} \alpha\left(I_{j}^{2} R_{j}\left(I_{j}\right) \frac{36 C}{I_{j}}+\sum_{k=1}^{\frac{36 C}{I_{j}}}\left[I _ { j } \left(1-e^{\left.-\frac{k}{R_{1, j}\left(I_{j}\right) C_{1, j}\left(I_{j}\right)}\right)}+\frac{U_{1, j}}{R_{1, j}\left(I_{j}\right)} e^{\left.-\frac{k}{R_{1, j}\left(I_{j}\right) C_{1, j}\left(I_{j}\right)}\right]} R_{1, j}\left(I_{j}\right)\right.\right.\right. \\
\quad+(1-\alpha) M \frac{36 C}{I_{j}}
\end{array}\right\}
$$

where $\alpha$ is the obtained weighting factor, which could be adjusted between 0 and 1 to achieve the optimization of different focus on charging time and energy loss. $M$ serves as the compensating coefficient, which allows the charging time and energy loss to share the same order of magnitude. The control variable is $I_{j}$, i.e., the charging current in the charging stage, and the state variable is the voltage $U_{1, j}$ at the ends of the polarization resistance $R_{1, j}\left(I_{j}\right)$ at the beginning of each charging stage.

Owing to the parallel connection of polarization resistance and polarization capacitor in the equivalent circuit model, the voltage drop in the polarization resistance cannot be changed suddenly, and hence, the initial over-voltage of each charging stage is equal to the termination over-voltage of the corresponding previous charging stage. Accordingly, the initial over-voltage $U_{1, j}$ of each charging stage is chosen as the state variable, and the state transfer equation is:

$$
\begin{aligned}
& {\left[I_{j}\left(1-e^{-\frac{36 C / I_{j}}{R_{1, j}\left(I_{j}\right) C_{1, j}\left(I_{j}\right)}}\right)+\frac{U_{1, j}}{R_{1, j}\left(I_{j}\right)} e^{-\frac{36 C / I_{j}}{R_{1, j}\left(\mathrm{C}_{j}\right) C_{1, j}\left(I_{j}\right)}}\right] R_{1, j}\left(I_{j}\right)=U_{1(j+1)}} \\
& j=1,2 \ldots N N-1
\end{aligned}
$$

The boundary conditions of the charge currents indicate that, when the SOC is large, the charging current is small, which leads to the slow charging of the last few stages. At the end of the charge, it is believed that the current in the polarization resistance reaches the steady state value $\mathrm{I}_{\mathrm{N}}$. Thus, according to (16), the initial over-voltage during the final charging phase can be obtained, i.e., the state variables $U_{1, N}=R_{1, N}\left(I_{N}\right) \times I_{N}$ At the initial stage of charging, the state variable of such a phase is $\mathrm{U}_{1,1}=0$, because the voltage of polarization resistance is zero. 


\subsection{Solution of Charging Current using a Dynamic Programming Algorithm}

Dynamic programming theory, proposed by the U.S. mathematician R. Bellman, is an overall optimization method aiming to transform complex decision problems into a series of sub-stage decision problems, and it has been widely used in offline global optimization of nonlinear systems. In this study, the charging method is based on the battery equivalent dynamic model, and the parameters of the model are nonlinear with the changes of SOC and charging current. Therefore, the dynamic programming algorithm is suitable for solving the current of the proposed charging method. The dynamic programming model for obtaining the charging current is shown in Table 2.

Table 2. Mathematical model of dynamic programming algorithm.

\begin{tabular}{|c|c|}
\hline $\begin{array}{c}\text { Phase } \\
\text { variables }\end{array}$ & $\begin{array}{l}\text { The charge stage is divided according to } \triangle \mathrm{SOC} \text {; each charging stage is denoted by } \\
\qquad \mathrm{j}=1,2, \ldots, \mathrm{N}\end{array}$ \\
\hline State variables & $\mathrm{U}_{1, \mathrm{j}}$ is the over-voltage at the initial moment of the $\mathrm{jth}$ charging phase. \\
\hline Decision variable & $\mathrm{I}_{\mathrm{j}}$ is the charging current during the jth charging phase. \\
\hline $\begin{array}{l}\text { Enable decision } \\
\text { collection }\end{array}$ & $\mathrm{D}_{\mathrm{j}}\left(\mathrm{I}_{\mathrm{j}}\right)=\left\{0 \leq \mathrm{I}_{\mathrm{j}} \leq \mathrm{I}_{\max }(\Delta \mathrm{SOC}) \times \mathrm{j}\right\}$ \\
\hline $\begin{array}{l}\text { State } \\
\text { transfer equation }\end{array}$ & $\left\{\begin{array}{l}U_{1, j+1}=\phi\left(U_{j}, I_{j}\right)=\left[I_{j}\left(1-e^{-\frac{36 C / I_{j}}{R_{1, j}\left(I_{j}\right) C_{1, j}\left(I_{j}\right)}}\right)+\frac{U_{1, j}}{R_{1, j}\left(I_{j}\right)} e^{-\frac{36 C / I_{j}}{R_{1, j}\left(I_{j}\right) C_{1, j}\left(I_{j}\right)}}\right] R_{1, j}\left(I_{j}\right) \\
j=1,2 \ldots N N-1 \\
U_{1, N}=R_{1, N}\left(I_{N}\right) I_{N} \\
U_{1,1}=0\end{array}\right.$ \\
\hline Reward function & $\begin{aligned} V_{j}\left(I_{j}, U_{j}\right) & =\alpha\left(I_{j}^{2} R_{j}\left(I_{j}\right) \frac{36 C}{I_{j}}+\sum_{k=1}^{\frac{36 C}{I_{j}}}\left[I_{j}\left(1-e^{-\frac{k}{R_{1, j}\left(I_{j}\right) C_{1, j}\left(I_{j}\right)}}\right)+\frac{U_{1, j}}{R_{1, j}\left(I_{j}\right)} e^{-\frac{k}{R_{1, j}\left(I_{j}\right) C_{1, j}\left(I_{j}\right)}}\right]^{2} R_{1, j}\left(I_{j}\right)\right) \\
+ & (1-\alpha) M \frac{36 C}{I_{j}}\end{aligned}$ \\
\hline $\begin{array}{l}\text { Objective value } \\
\text { function }\end{array}$ & $\mathrm{f}_{\mathrm{j}}\left(\mathrm{U}_{1, \mathrm{j}}\right)=\min _{\mathrm{I}_{\mathrm{j}} \in \mathrm{D}_{\mathrm{j}}\left(\mathrm{I}_{\mathrm{j}}\right)}\left[\mathrm{v}_{\mathrm{j}}\left(\mathrm{I}_{\mathrm{j}}, \mathrm{U}_{1 \mathrm{j}}\right)+\mathrm{f}_{\mathrm{j}+1}\left(\mathrm{U}_{\mathrm{j}+1}\right)\right]$ \\
\hline
\end{tabular}

The inverse solution method is used to solve the problem. The $\mathrm{N}+1$ charging stage is added as the boundary condition and the objective value function at this stage is zero, i.e., $\mathrm{f}_{\mathrm{N}+1}=0$. First, the extreme value of $f_{N}$ is obtained; further, the expression of optimal charging current in the $N$ stage is obtained, which is $I_{N, \text { opt }}=M_{N}\left(U_{1, N}\right)$. Second, if $U_{1, N}$ and $I_{N, \text { opt }}$ are used for obtaining $f_{N}$, the $f_{N}$ expression about $U_{1, N}$ is obtained, which is $P_{N}\left(U_{1, N}\right)$, According to the state transfer equation, $\mathrm{P}_{\mathrm{N}}\left(\mathrm{U}_{1, \mathrm{~N}}\right)$ can be further expressed as $\mathrm{P}_{\mathrm{N}}\left(\phi\left(\mathrm{U}_{1, \mathrm{~N}-1}, \mathrm{I}_{\mathrm{N}-1}\right)\right)$. After storing $\mathrm{I}_{\mathrm{N}, \mathrm{opt}}$ and $\mathrm{f}_{\mathrm{N}}$, the same method is used to calculate $\mathrm{f}_{\mathrm{N}-1}$, and the expressions of $\mathrm{I}_{\mathrm{N}-1, \mathrm{opt}}$ and $\mathrm{f}_{\mathrm{N}-1}$ are represented as $\mathrm{M}_{\mathrm{N}-1}\left(\mathrm{U}_{1, \mathrm{~N}-1, \mathrm{opt}}\right)$ and $\mathrm{P}_{\mathrm{N}-1}\left(\phi\left(\mathrm{U}_{1, \mathrm{~N}-2,}, \mathrm{I}_{\mathrm{N}-2}\right)\right)$, respectively. After storing $\mathrm{I}_{\mathrm{N}-1, \text { opt }}$ and $\mathrm{f}_{\mathrm{N}-1}, \mathrm{f}_{\mathrm{N}-2}$ is calculated. Thus, this process is performed step by step, obtaining each stage of the charging current $\mathrm{I}_{\mathrm{j}, \mathrm{opt}}$ in the expression for $\mathrm{U}_{1, \mathrm{j}}$, i.e., $\mathrm{Mj}(\mathrm{U} 1, \mathrm{j})$. According to the initial condition $\mathrm{U}_{1,1}=0$ and the state transition equation $\mathrm{U}_{1, \mathrm{j}}=\phi\left(\mathrm{U}_{1, \mathrm{j}-1}, \mathrm{I}_{\mathrm{j}-1}\right)$, the optimal charging current $\mathrm{I}_{\mathrm{j}}$ at each stage is calculated. The solution flow is shown in Figure 8. 


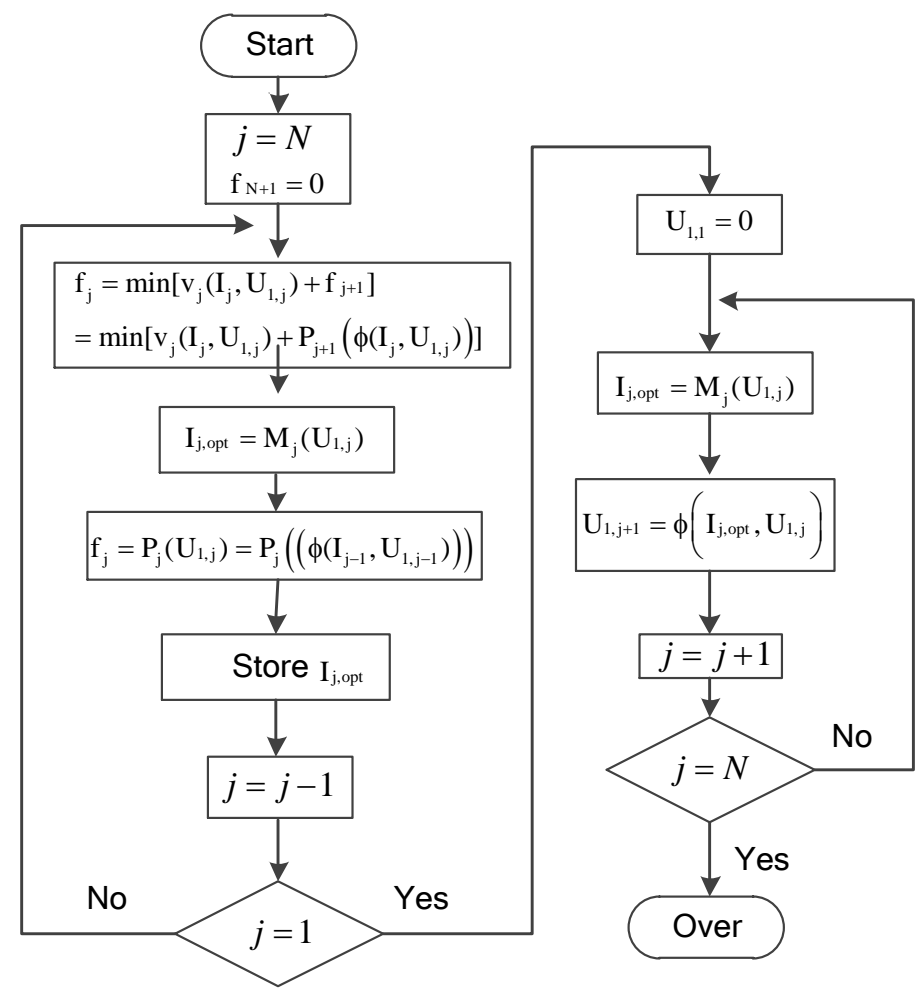

Figure 8. Flowchart of dynamic programming algorithm adopted to obtain current.

\section{Analysis of Simulation and Experimental Results}

\subsection{Optimization Results for Different Weighting Factors}

When the weighting factor changes from 0 to 1 in the optimization target, the optimization result of the proposed charging method is shown in Figure 9. The charging range of the battery corresponding to each weighting factor is in the range of 0 to $95 \%$ of SOC.

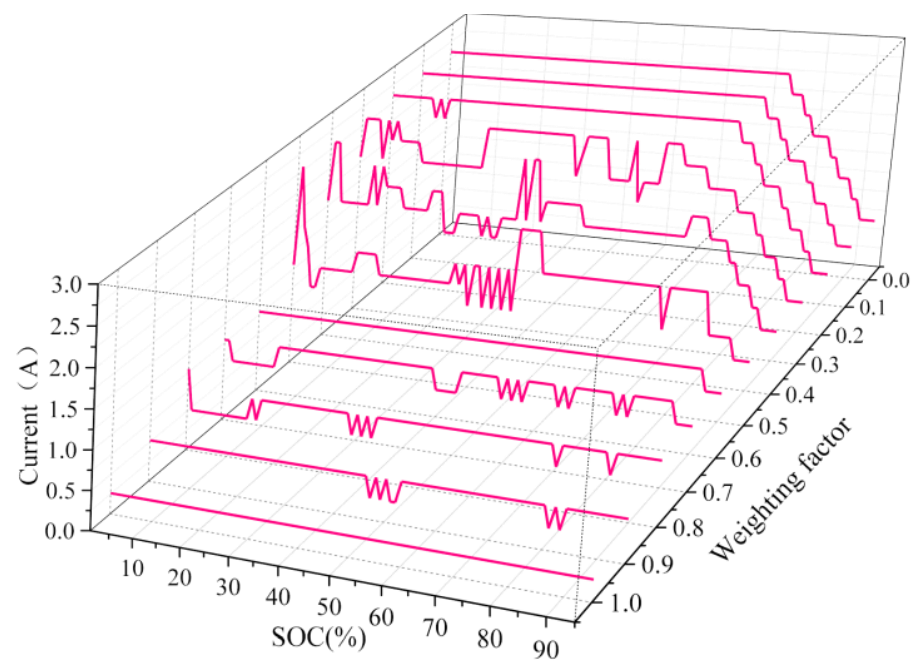

(a)

Figure 9. Cont. 


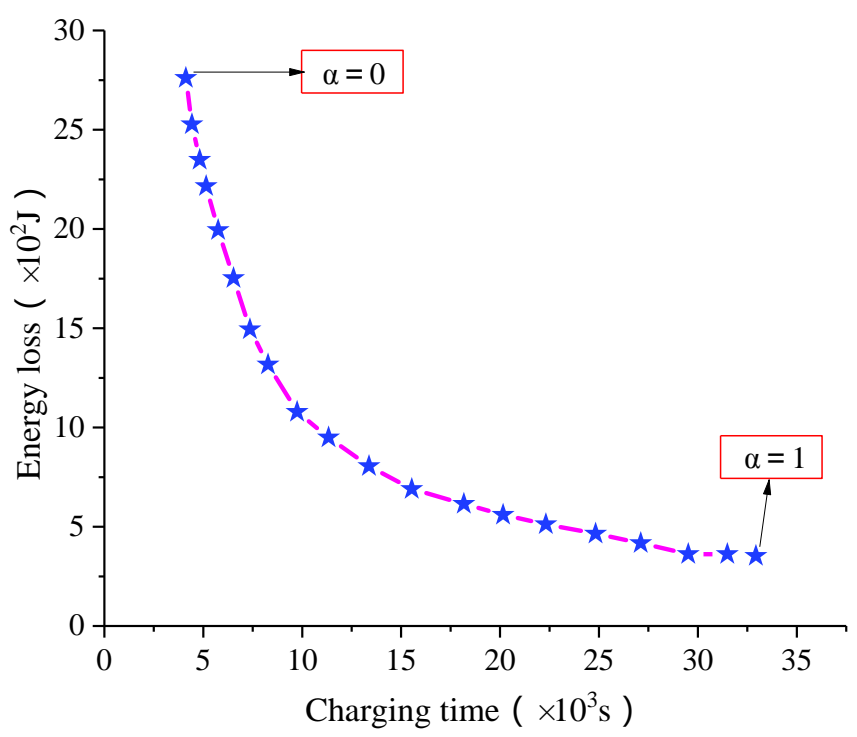

(b)

Figure 9. Comparison between charging current curves for different weights and charging time and energy loss for different weights. (a) Charging current curve; (b) Charging time and energy loss.

Figure 9a illustrates an optimized charge current curve for different weighting factors, and Figure $9 \mathrm{~b}$ illustrates the time and energy loss for different weighting factors corresponding to the proposed charging method. It can be observed from the graph that, when the charging time decreases, the battery energy loss increases, which indicates that the two problems are contradictory with respect to the optimization of battery charging.

\subsection{Analysis of the Weighting Factors}

In order to verify the effectiveness of the proposed charging method and to provide reference for selecting the optimum weighting factor, this study has compared the proposed method and the CCCV charging method. The weighting factor of the proposed method is in the range of $0.1-0.9$, whereas the charging current ratio of the CCCV charging method is $0.5 \mathrm{C}$. The charging range is in the $\mathrm{SOC}$ range of 0 to $95 \%$. The charging time and battery energy loss of both these methods are demonstrated in Table 3.

Table 3. Time and energy loss of the proposed charging method and CCCV charging method.

\begin{tabular}{|c|c|c|c|c|}
\hline \multicolumn{3}{|c|}{ Charging Method } & \multirow{2}{*}{$\begin{array}{c}\text { Time (s) } \\
4111\end{array}$} & \multirow{2}{*}{$\begin{array}{c}\text { Energy Loss }(\mathrm{J}) \\
2760\end{array}$} \\
\hline \multirow{9}{*}{$\begin{array}{l}\text { Proposed charging } \\
\text { method }\end{array}$} & \multirow{9}{*}{$\begin{array}{l}\text { Weigh-ting } \\
\text { factor }\end{array}$} & 0.1 & & \\
\hline & & 0.2 & 4119 & 2715 \\
\hline & & 0.3 & 4433 & 2527 \\
\hline & & 0.4 & 5143 & 2216 \\
\hline & & 0.5 & 6534 & 1752 \\
\hline & & 0.6 & 8670 & 1239 \\
\hline & & 0.7 & 9330 & 1146 \\
\hline & & 0.8 & 12,510 & 871 \\
\hline & & 0.9 & 18,180 & 615 \\
\hline \multicolumn{3}{|c|}{$\mathrm{CCCV}$} & 7076 & 1853 \\
\hline
\end{tabular}

The comparison between the two charging methods assumes the following approach:

$$
\gamma_{\alpha, t}=\frac{t_{\mathrm{cccv}}-t_{\alpha}}{t_{\mathrm{cccv}}} \times 100 \%
$$




$$
\gamma_{\alpha, \mathrm{E}}=\frac{\mathrm{E}_{\mathrm{cccv}}-\mathrm{E}_{\alpha}}{\mathrm{E}_{\mathrm{cccv}}} \times 100 \%
$$

The aforementioned equations present the percentage time and energy consumption, respectively, of the optimal charging method when compared to the CCCV charging method; $t_{\alpha}$ and $E_{\alpha}$, respectively, represent the time and energy loss of the proposed charging method corresponding to the weighting factor $\alpha ; \mathrm{t}_{\mathrm{CCCV}}$ and $\mathrm{E}_{\mathrm{CCCV}}$, respectively, represent the time and energy loss of the CCCV charging method of 0.5C. The comparison results are shown in Figure 10. When 'Energy save' or 'Time reduce' is positive, it means that the proposed charging method is superior to the constant current constant voltage charging method in reducing the energy loss or reducing the charging time, and the greater the absolute value of 'Energy save' or 'Time reduce', the better the optimization effect and vice versa.

As evident from Figure 10, compared with the CCCV charging method of $0.5 \mathrm{C}$, when the weighting factor is $0.1-0.4$, the charging method can reduce the charging time, but the energy loss is increased. However, when the weighting factor is $0.6-0.9$, the charging method can reduce the energy loss, but the charging time increases. It is only at the weighting factor of 0.5 that the energy loss decreases by $5.45 \%$ and the charging time decreases by $7.66 \%$. This results in a trade-off in optimizing charging time and energy loss in order to change the charging current according to the changes of the internal parameters of the battery along with the changes of the SOC When the internal resistance of the SOC is relatively large, the charging current of the optimized calculation can be relatively reduced in order to reduce the energy consumption of the battery. When the resistance value corresponding to the SOC is small, the optimized calculation of the charging current can be appropriately improved in order to reduce the charging time.

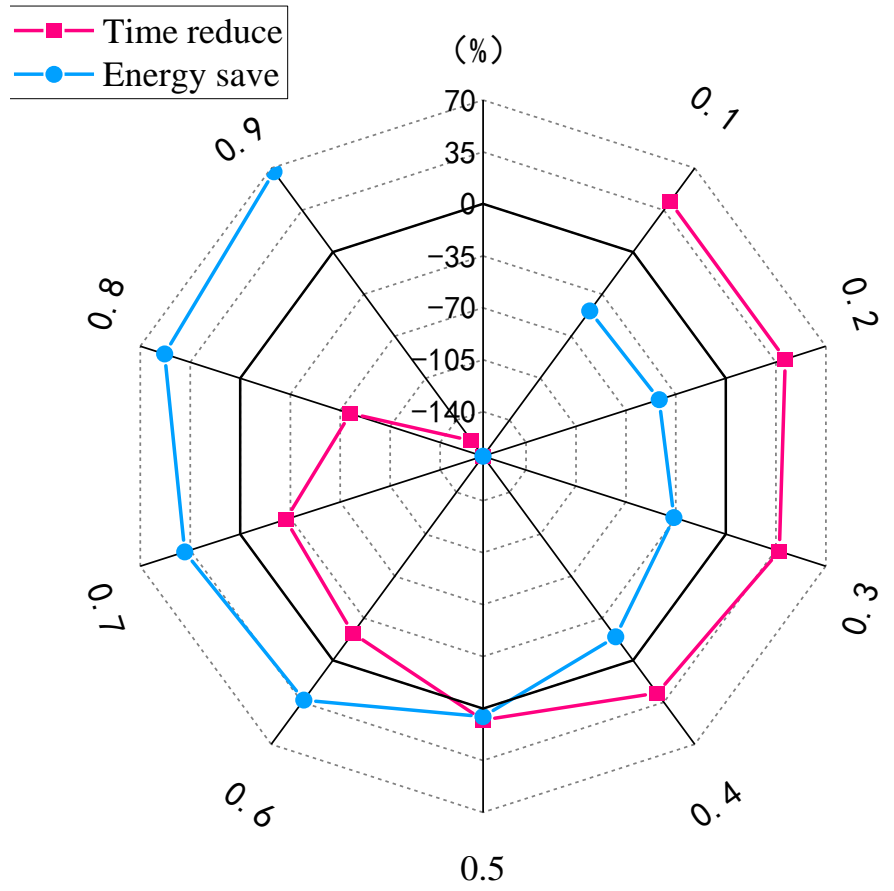

Figure 10. Comparison between charging method and CCCV charging method for different weight factors.

This study uses the surface temperature of the battery to reflect the energy loss in the charging process indirectly. Figure 11 illustrates the comparison between the proposed charging method with weight factor of 0.5 and $\mathrm{CCCV}$ charging method of $0.5 \mathrm{C}$ in the charging. The charging range is the SOC of 0 to $95 \%$. 


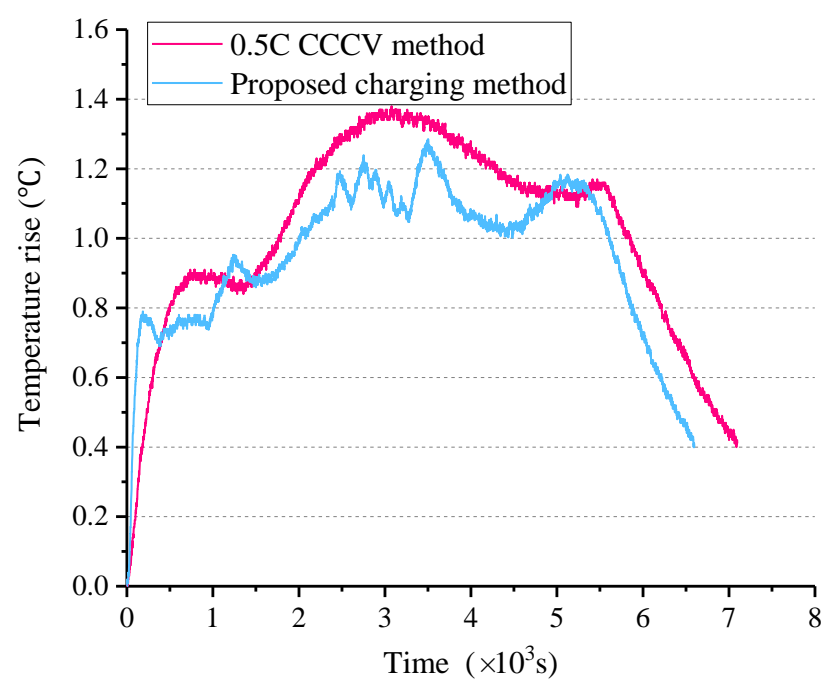

Figure 11. Surface temperature rise of the battery during the charging process.

As evident from Figure 11, the maximum temperature rise, average temperature rise, and charging time of the proposed charging method for the weighting factor of 0.5 are reduced, as compared to the $\mathrm{CCCV}$ charging method of $0.5^{\circ} \mathrm{C}$. The effectiveness of the charging method proposed in this paper and the rationality behind choosing the charging method with the weighting factor of 0.5 to optimize the charging time and energy loss are explained.

\subsection{Attenuation Comparison of Battery Capacity}

In order to evaluate the charging method objectively, this study performs a comparative analysis between the charging method and CCCV charging method from the perspective of battery capacity attenuation. The empirical formula describing the decay of battery life can be obtained from literature [35]:

$$
\text { Cap }_{\text {loss }}=\mathrm{k} \times \mathrm{x}^{\delta}
$$

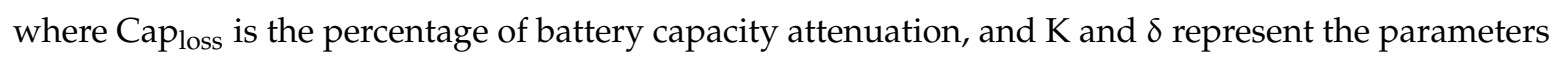
related to battery charge-discharge ratio and charge-discharge cut-off voltage and temperature; further, $x$ represents the battery charge-discharge cycles or the throughput capacity of the battery. In literature [35], the relationship between the parameters and the charge-discharge ratio was calibrated at $25{ }^{\circ} \mathrm{C}$ with the lithium-ion battery which considers the cathode material as $\mathrm{LiCoO}_{2}$ and the anode material as graphite. Specifically, $x$ represents charge-discharge cycles and the calibration results are shown in Table 4.

Table 4. Calibration results for parameters $\mathrm{k}$ and $\delta$.

\begin{tabular}{cccc}
\hline Charge-Discharge Rate & $\mathbf{0 . 5 C}$ & $\mathbf{0 . 8 C}$ & $\mathbf{1 C}$ \\
\hline $\mathrm{k}$ & 0.0121 & 0.0116 & 0.0141 \\
$\delta$ & 1.152 & 1.183 & 1.17 \\
\hline
\end{tabular}

In order to apply the model of battery decay and calibration parameters of [35] to the research in this study, the aging model has been further deduced, and (19) can be changed to:

$$
\mathrm{Cap}_{\text {loss }}=\mathrm{k} \times\left(\frac{\mathrm{Ah}}{2 \mathrm{Cap}}\right)^{\delta}
$$

where Ah represents the throughput capacity of the battery. Further, (20) can be modified to: 


$$
\mathrm{Ah}=2 \mathrm{Cap} \times\left(\frac{\mathrm{Cap}_{\text {loss }}}{\mathrm{k}}\right)^{\frac{1}{\delta}}
$$

By using (20) to achieve the derivation of Ah, we obtain:

$$
\operatorname{Cap}_{\text {loss }}=\frac{\delta \mathrm{k}}{2 \mathrm{Cap}}\left(\frac{\mathrm{Ah}}{2 \mathrm{Cap}}\right)^{\delta-1}
$$

Substituting (21) into (22) in order to achieve difference, we obtain:

$$
\text { Cap }_{\text {loss }, \mathrm{p}+1}=\mathrm{Cap}_{\text {loss }, \mathrm{p}}+\frac{\delta\left(\mathrm{I}_{\mathrm{p}}\right) \mathrm{k}\left(\mathrm{I}_{\mathrm{p}}\right)}{2 \mathrm{Cap}}\left(\frac{\mathrm{Cap}_{\text {loss }, \mathrm{p}}}{\mathrm{k}\left(\mathrm{I}_{\mathrm{p}}\right)}\right)^{\frac{\delta-1}{\delta}} \Delta \mathrm{Ah}_{\mathrm{p}}
$$

where Cap loss, $\mathrm{p}+1$ and Cap $\mathrm{P}_{\text {loss, } \mathrm{p}}$, respectively, represent the cumulative loss of the battery at $\mathrm{p}$ and $p+1$ moments, and $\Delta \mathrm{Ah}_{\mathrm{p}}$ represents the throughput capacity of the battery during the $\mathrm{p}$ to $\mathrm{p}+1$ interval, i.e.,

$$
\Delta \mathrm{Ah}_{\mathrm{p}}=\frac{1}{3600} \int_{\mathrm{t}_{\mathrm{p}}}^{\mathrm{t}_{\mathrm{p}+1}}\left|\mathrm{I}_{\mathrm{p}}\right| \mathrm{dt}
$$

According to (20), we obtain:

$$
\text { Capp }_{\text {loss }, 1}=\mathrm{k}\left(\mathrm{I}_{1}\right) \times\left(\frac{\Delta \mathrm{Ah}_{1}}{2 \mathrm{Cap}}\right)^{\delta\left(\mathrm{I}_{1}\right)}
$$

In the battery attenuation model adopted in this study, the charge-discharge current of the battery has a significant influence on the battery attenuation. In order to evaluate the advantages of the charging method proposed in this paper, the $0.5 \mathrm{C}$ current ratio will be unified used when discharging during the battery charge and discharge testing process. After multiple charge and discharge cycles, compared with the optimized charging method corresponding to the weighting factor of 0.5 and the CCCV charging method, the decay of battery capacity attenuation is shown in Figure 12. Further, the relative capacity decay rate $\mu$ is calculated as:

$$
\mu=\frac{\text { Cap }_{\text {loss,opt }}-\text { Cap }_{\text {loss }, \mathrm{cccv}}}{\text { Cap }_{\text {loss }, \mathrm{ccc}}} \times 100 \%
$$

where Cap ${ }_{\text {loss,opt }}$ and Cap loss,cccv represent the percentage of the battery capacity attenuation of the proposed charging method and CCCV voltage charging method of $0.5 \mathrm{C}$, respectively,

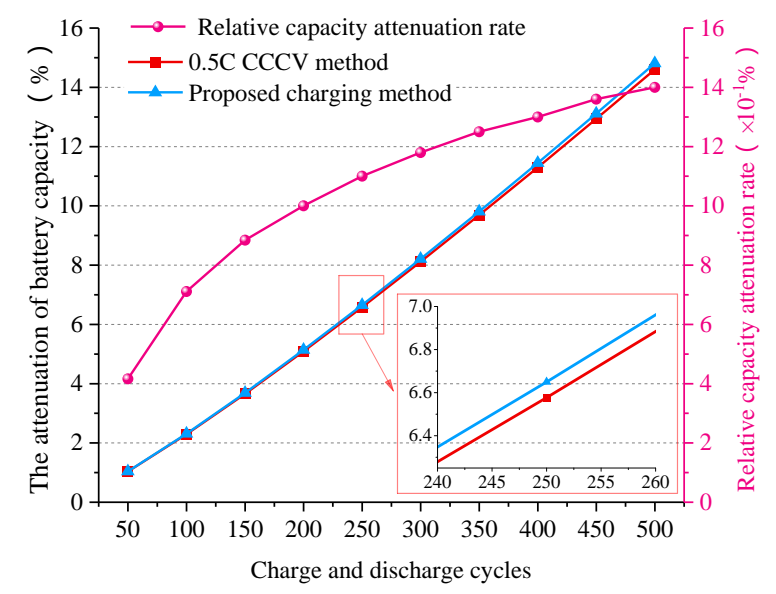

Figure 12. Effect of the two charging methods on the attenuation of battery capacity. 
It can be observed in Figure 12 that, compared with the traditional CCCV charging method, a similarity can be observed in the effect of the optimized charging method on the declining battery life. Reference [36] indicates that lithium cobalt acid batteries are mainly applied in portable mobile electronics. If the electronic products are only used for one year and the daily charge is indispensable, compared to the CCCV charging method, the proposed method reduces the charging time and energy consumption by $7.66 \%$ and $5.45 \%$, respectively, by adopting the charging method proposed in this paper, whereas the capacity attenuation increases by merely $1.25 \%$.

Therefore, considering the influence of charging time, battery energy consumption, and capacity attenuation, the charging method proposed in this paper can effectively reduce the charging time and battery energy loss without accelerating the attenuation of the battery capacity.

\section{Conclusions}

By establishing a first-order dynamic equivalent circuit model of the battery and realizing parameter identification, a charging method that considers the battery charging time and battery energy loss as the optimized objectives has been proposed in this paper, and the optimal current value has been obtained by using dynamic programming. According to the simulation and experimental results, during charging, reducing the time and reducing the energy loss are contradictory problems; therefore, the charging curve can be obtained with different emphasis on charging time and energy loss by changing the weighting factor. The results of discussion on the weighting factors in this paper are as follows. Compared with the CCCV charging method, when the weighting factor is 0.5 , the energy loss and time are reduced by $5.45 \%$ and $7.66 \%$, respectively, whereas the effect of the two charging methods on the attenuation of the battery capacity is almost the same. Therefore, the multi-objective optimal charging method can effectively solve the comprehensive optimization problem of the charging time and energy loss.

Acknowledgments: This work is sponsored by the National Key Technologies R\&D Program of MOST (2016YFB0101801); Scholarship of State Key Laboratory of Power Transmission Equipment \& System Security and New Technology (Chongqing University) (2007DA10512716416); Science Funds for the Young Innovative Talents of HUST, No. 201503.

Author Contributions: Xiaogang Wu and Wenwen Shi conceived and designed the Testing and simulations; Xiaogang Wu analyzed the data; Wenwen Shi wrote the paper; Jiuyu Du checked the paper.

Conflicts of Interest: The authors declare no conflict of interest.

\section{Appendix A}

List of symbols.

\begin{tabular}{llll}
\hline Symbol & Significance & Symbol & Significance \\
\hline $\mathrm{R}_{0}$ & Ohmic resistance & $\mathrm{I}_{\max }$ & Maximum charging current \\
$\mathrm{R}_{1}$ & polarization resistance & $\xi$ & percentage of maximum charge capacity \\
$\mathrm{C}_{1}$ & polarization capacitance & $\mathrm{W}$ & energy loss \\
$\mathrm{U}_{\mathrm{OC}}$ & open-circuit voltage & $\mathrm{I}$ & Charging current \\
$\tau_{\mathrm{t}}$ & voltage error & $\mathrm{W}_{1}$ & energy loss of the polarization resistance \\
$\mathrm{U}_{\mathrm{t}, \mathrm{r}}$ & actual value of the battery terminal voltage & $\mathrm{Cap}$ & battery rated capacity \\
$\mathrm{U}_{\mathrm{t}, \mathrm{s}}$ & simulation value of the battery terminal voltage & $\eta$ & Coulomb efficiency \\
$\mathrm{SOC}$ & State of charge & $\Delta_{\mathrm{j}}$ & charging time of each charging phase \\
$\Delta \mathrm{t}$ & sampling time & $\gamma_{\alpha, \mathrm{t}}$ & Time reduce \\
$\mathrm{T}$ & charging time & $\gamma_{\alpha, \mathrm{E}}$ & Energy save \\
$\mathrm{f}$ & objective function & $\mathrm{x}$ & throughput capacity \\
$\alpha$ & weighting factor & Cap & percentage of battery capacity attenuation \\
$\mathrm{M}$ & compensating coefficient & $\mu$ & relative capacity decay rate \\
$\mathrm{j}$ & charging stage & & \\
\hline
\end{tabular}




\section{References}

1. Du, J.; Ouyang, M.; Chen, J. Prospects for Chinese electric vehicle technologies in 2016-2020: Ambition and rationality. Energy 2017, 120, 584-596. [CrossRef]

2. Pattipati, B.; Sankavaram, C.; Pattipati, K. System Identification and Estimation Framework for Pivotal Automotive Battery Management System Characteristics. IEEE Trans. Syst. Man Cybern. Part C 2011, 41, 869-884. [CrossRef]

3. Xiong, R.; Zhang, Y.; He, H.; Zhou, X.; Pecht, M.G. A double-scale, particle-filtering, energy state prediction algorithm for lithium-ion batteries. IEEE Trans. Ind. Electron. 2017, PP, 1. [CrossRef]

4. Sun, X.; Yamamoto, T.; Morikawa, T. Charge timing choice behavior of battery electric vehicle users. Transp. Res. Part D 2015, 37, 97-107. [CrossRef]

5. Du, J.; Chen, J.; Song, Z.; Ouyang, M. Design method of a power management strategy for variable battery capacities range-extended electric vehicles to improve energy efficiency and cost-effectiveness. Energy 2017, 121, 32-42. [CrossRef]

6. Wang, J.; Liu, P.; Hicks-Garner, J.; Sherman, E.; Soukiazian, S.; Verbrugge, M.; Tataria, H.; Musser, J.; Finamore, P. Cycle-life model for graphite-LiFePO4 cells. J. Power Sources 2011, 196, 3942-3948. [CrossRef]

7. Zhang, C.; Jiang, J.; Gao, Y.; Zhang, W.; Liu, Q. Charging optimization in lithium-ion batteries based on temperature rise and charge time. Appl. Energy 2017, 194, 569-577. [CrossRef]

8. Nafisi, H.; Askarian Abyaneh, H.; Abedi, M. Energy loss minimization using PHEVs as distributed active and reactive power resources: A convex quadratic local optimal solution. Int. Trans. Electr. Energy Syst. 2016, 26, 1287-1302. [CrossRef]

9. Du, J.; Ouyang, D. Progress of Chinese electric vehicles industrialization in 2015: A review. Appl. Energy 2017, 188, 529-546. [CrossRef]

10. Han, X.; Ouyang, M.; Lu, L.; Li, J. A comparative study of commercial lithium ion battery cycle life in electric vehicle: Capacity loss estimation. J. Power Sources 2014, 268, 658-669. [CrossRef]

11. Ikeya, T.; Sawada, N.; Murakami, J.; Kobayashi, K.; Hattori, M.; Murotani, N.; Ujiie, S.; Kajiyama, K.; Nasu, H.; Narisoko, H.; et al. Multi-step constant-current charging method for an electric vehicle nickel/metal hydride battery with high-energy efficiency and long cycle life. J. Power Sources 2002, 105, 6-12. [CrossRef]

12. Vo, T.T.; Chen, X.; Shen, W.; Kapoor, A. New charging strategy for lithium-ion batteries based on the integration of Taguchi method and state of charge estimation. J. Power Sources 2015, 273, 413-422. [CrossRef]

13. Notten, P.H.L.; Veld, J.H.G.O.; Beek, J.R.G.V. Boostcharging Li-ion batteries: A challenging new charging concept. J. Power Sources 2005, 145, 89-94. [CrossRef]

14. An, S.J.; Li, J.; Du, Z.; Daniel, C.; Wood, D.L. Fast formation cycling for lithium ion batteries. J. Power Sources 2017, 342, 846-852. [CrossRef]

15. An, S.J.; Li, J.; Daniel, C.; Mohanty, D.; Nagpure, S.; Wood, D.L. The state of understanding of the lithium-ion-battery graphite solid electrolyte interphase (SEI) and its relationship to formation cycling. CARBON 2016, 105, 52-76. [CrossRef]

16. Li, J.; Du, Z.; Ruther, R.E.; AN, S.J.; David, L.A.; Hays, K.; Wood, M.; Phillip, N.D.; Sheng, Y.; Mao, C.; et al. Toward Low-Cost, High-Energy Density, and High-Power Density Lithium-Ion Batteries. JOM-US 2017, 69, 1484-1496. [CrossRef]

17. James, M.; Grummett, J.; Rowan, M.; Newman, J. Application of pulse charging techniques to submarine lead-acid batteries. J. Power Sources 2006, 62, 878-883. [CrossRef]

18. Chen, L.R. Design of Duty-Varied Voltage Pulse Charger for Improving Li-Ion Battery-Charging Response. IEEE Trans. Ind. Electron. 2012, 56, 480-487. [CrossRef]

19. Kalla, U.K.; Suthar, R.; Singh, B.; Sharma, K.; Singhal, J. Generalized electronic controller for multi-pulse battery charging systems. In Proceedings of the 6th IEEE International Conference on Power Systems, New Delhi, India, 4-6 March 2016.

20. Savoye, F.; Venet, P.; Millet, M.; Groot, J. Impact of Periodic Current Pulses on Li-Ion Battery Performance. IEEE Trans. Ind. Electron. 2012, 59, 3481-3488. [CrossRef]

21. Guo, Z.; Liaw, B.Y.; Qiu, X.; Gao, L.; Zhang, C. Optimal charging method for lithium ion batteries using a universal voltage protocol accommodating aging. J. Power Sources 2015, 274, 957-964. [CrossRef]

22. Hu, X.; Li, S.; Peng, H.; Sun, F. Charging time and loss optimization for LiNMC and $\mathrm{LiFePO}_{4}$ batteries based on equivalent circuit models. J. Power Sources 2013, 239, 449-457. [CrossRef] 
23. Abdollahi, A.; Han, X.; Avvari, G.V.; Raghunathan, N.; Balasingam, B.; Pattipati, K.R.; Bar-Shalom, Y. Optimal battery charging, Part I: Minimizing time-to-charge, energy loss, and temperature rise for OCV-resistance battery model. J. Power Sources 2016, 303, 388-398. [CrossRef]

24. Liu, W.; Wu, C.; He, Z.; Sun, X.; Yang, G. A Multi-Stage Constant Current Charging Method Considering Internal Energy Loss and Charging Speed of Lithium Batteries. Trans. China Electrotech. Soc. 2017, 32, 112-120.

25. He, H.; Xiong, R.; Guo, H.; Li, S. Comparison study on the battery models used for the energy management of batteries in electric vehicles. Energy Convers Manag. 2012, 64, 113-121. [CrossRef]

26. Sun, F.; Xiong, R.; He, H. A systematic state-of-charge estimation framework for multi-cell battery pack in electric vehicles using bias correction technique. Appl. Energy 2016, 162, 1399-1409. [CrossRef]

27. Hu, X.; Li, S.; Peng, H. A comparative study of equivalent circuit models for Li-ion batteries. J. Power Sources 2012, 198, 359-367. [CrossRef]

28. Xiong, R.; Yu, Q.; Wang, L.Y.; Lin, C. A novel method to obtain the open circuit voltage for the state of charge of lithium ion batteries in electric vehicles by using $\mathrm{H}$ infinity filter. Appl. Energy 2017. [CrossRef]

29. Tsang, K.M.; Sun, L.; Chan, W.L. Identification and modelling of Lithium ion battery. Energy Convers Manag. 2010, 51, 2857-2862. [CrossRef]

30. Zahid, T.; Li, W. A Comparative Study Based on the Least Square Parameter Identification Method for State of Charge Estimation of a $\mathrm{LiFePO}_{4}$ Battery Pack Using Three Model-Based Algorithms for Electric Vehicles. Energies 2016, 9, 720. [CrossRef]

31. Zhang, S.; Zhang, C.; Xiong, R.; Zhou, W. Study on the Optimal Charging Strategy for Lithium-Ion Batteries Used in Electric Vehicles. Energies 2014, 7, 6783-6797. [CrossRef]

32. Zhang, B.; Chen, M.; Yang, D. Investigation of the polarization effect in lithium iron phosphate battery for electric vehicles. In Proceedings of the 2014 IEEE Conference and Expo Transportation Electrification Asia-Pacific (ITEC Asia-Pacific), Beijing, China, 31 August-3 September 2014.

33. Groot, J.; Swierczynski, M.; Stan, A.I.; Kær, S.K. On the complex ageing characteristics of high-power LiFePO 4/graphite battery cells cycled with high charge and discharge currents. J. Power Sources 2015, 286, 475-487. [CrossRef]

34. Xiong, R.; Tian, J.; Mu, H.; Wang, C. A systematic model-based degradation behavior recognition and health monitoring method for lithium-ion batteries. Appl. Energy 2017. [CrossRef]

35. Gao, Y.; Jiang, J.; Zhang, C.; Zhang, W.; Ma, Z. Lithium-ion battery aging mechanisms and life model under different charging stresses. J. Power Sources 2017, 356, 103-114. [CrossRef]

36. Huang, L.; Li, T.; Liu, C.; Quan, X.; Chen, L. Synergetic interactions improve cobalt leaching from lithium cobalt oxide in microbial fuel cells. Bioresour. Technol. 2013, 128, 539-546. [CrossRef] [PubMed]

(C) 2017 by the authors. Licensee MDPI, Basel, Switzerland. This article is an open access article distributed under the terms and conditions of the Creative Commons Attribution (CC BY) license (http:/ / creativecommons.org/licenses/by/4.0/). 